\title{
Mapping Migration across Generations
}

\author{
Gerrit Bloothooft $^{a}$, David Onland ${ }^{a}$ and Jan Pieter Kunst ${ }^{b}$ \\ ${ }^{a}$ Utrecht institute of Linguistics - OTS, Utrecht University, \\ ${ }^{b}$ Meertens Institute KNAW, Amsterdam, \\ Corresponding author: g.bloothooft@uu.nl
}

\begin{abstract}
Flexible software has been developed for the interactive mapping of socio-cultural phenomena in the Netherlands on the web. The possibilities of such software are demonstrated for the mapping of migration in the Netherlands across four generations. Both the origin and dispersion of the population can be explored at the geographic levels of municipality, region, dialect area and province.
\end{abstract}

\subsection{Introduction}

Most people leave their parental home as adolescents, taking with them their cultural capital, including language. If they remain close to their parents, family and social networks, local and regional traditions may endure. However, when there is a significant amount of long-distance migration, intercultural interactions may result in changes in their behaviour and identification. To understand such socio-cultural changes, including for instance dialectal variation, it is of interest to know how the composition of a population in a place or region varies over time and to visualise this complex process in an insightful way. Such a presentation requires both migration data and mapping software.

For the description of migration, full population data for the Netherlands was available, including place and year of birth, place of residence in 2006 and, most importantly and uniquely, family relations across four generations. These data can be used to show the roots of the inhabitants of any municipality (or a larger geographical entity) and their ancestors for up to four generations (great-grandparents) by means of place of birth (origin maps). Conversely, we can start with the inhabitants who were born in a municipality between 1880 and 1900 and trace the dispersion of their descendants over the following three generations both by means of the birthplace and place

How to cite this book chapter:

Bloothooft, G, Onland, D and Kunst, J.P. 2017. Mapping Migration across Generations. In: Odijk, J and van Hessen, A. (eds.) CLARIN in the Low Countries, Pp. 351-360. London: Ubiquity Press. DOI: https://doi.org/10.5334/bbi.29. License: CC-BY 4.0 
of residence in 2006 - these are the dispersion maps. For the visualisation of migration processes, mapping software has been developed., The software was designed for flexible online visualisation of linguistic-cultural phenomena in general, including an easy selection interface. The current application on migration is a demonstration of the possibilities of this software, and is available at www.meertens.knaw.nl/migmap. In the following sections, the properties of the underlying data are described, as well as the presentation options for migration maps, including some examples. A technical description of the mapping software is given in the appendix.

\subsection{Data}

\subsubsection{Population Data}

We investigated and mapped migration on the basis of the date and place of birth as well as the postal code of Dutch nationals in 2006. These data were a subset of the information which was made available to the Meertens Institute KNAW and Utrecht University from the Civil Registration (GBA, municipal personal records database) for onomastic research. ${ }^{1}$ The full corpus encompasses 22,274,761 individuals, including all 15.6 million Dutch nationals who lived in the Netherlands in 2006, and 6.6 million of their ancestors. For each individual alive in or after 1994 (the start of GBA digitisation; see Prins and Kuijper, 2007) information on both parents was also available (including their date and place of birth). On this basis, and through linking across generations, relations between up to four generations could be established in so far as the ancestors or descendants were part of the corpus.

As the first generation of interest we chose the 4.6 million individuals who were between 30 and 50 years of age in 2006. This is the age when families are usually settled, children are raised and most people stay in the same place. For this generation, 3.8 million parents, 3 million grandparents and 1.2 million great-grandparents are known. Because people share ancestors, it cannot be determined what part of the total number of ancestors are covered by the data. But, at the level of parents, the coverage should be fairly complete since in most cases the person-parent relationship is known through identifiers. Parents that died before 1994 have no personal record, which means that their parents (i.e. the grandparents of the first generation) will in turn be unknown. We estimate that a coverage of $95 \%$ at the grandparent level is realistic. Great-grandparents are only known for grandparents alive in 1994, and we estimate that the coverage at this level is around $50 \%$. In all, these figures suggest a sample that is sufficiently large to map migration. A comparison of the total number of births since 1880 as provided by Netherlands Statistics (CBS) and those reconstructed from the Civil Registration is presented in Figure 29.1.

Conversely, we started with 1.4 million individuals born in the Netherlands between 1880 and 1900. Based on birth figures from Netherlands Statistics we estimate this to be $60 \%$ of all births during this period, after correction for infant mortality. As the Civil Registration is fairly complete for births after around 1945, we assume that most descendants living in 2006 are present in our corpus: the result is 3.8 million children, 4.9 million grandchildren and 5.5 million great-grandchildren.

\subsubsection{Geographic Levels of Presentation}

The mapping of migration is always done at the level of municipalities, with the administrative situation in January 2007, when there were 443 municipalities, as a baseline. However, different geographic areas may be chosen as the basis for the search question. The largest of these is that of

\footnotetext{
${ }^{1}$ See the Dutch corpus of first names at www.meertens.knaw.nl/nvb and the Dutch corpus of family names at www.cbgfamilienamen.nl/nfb
} 


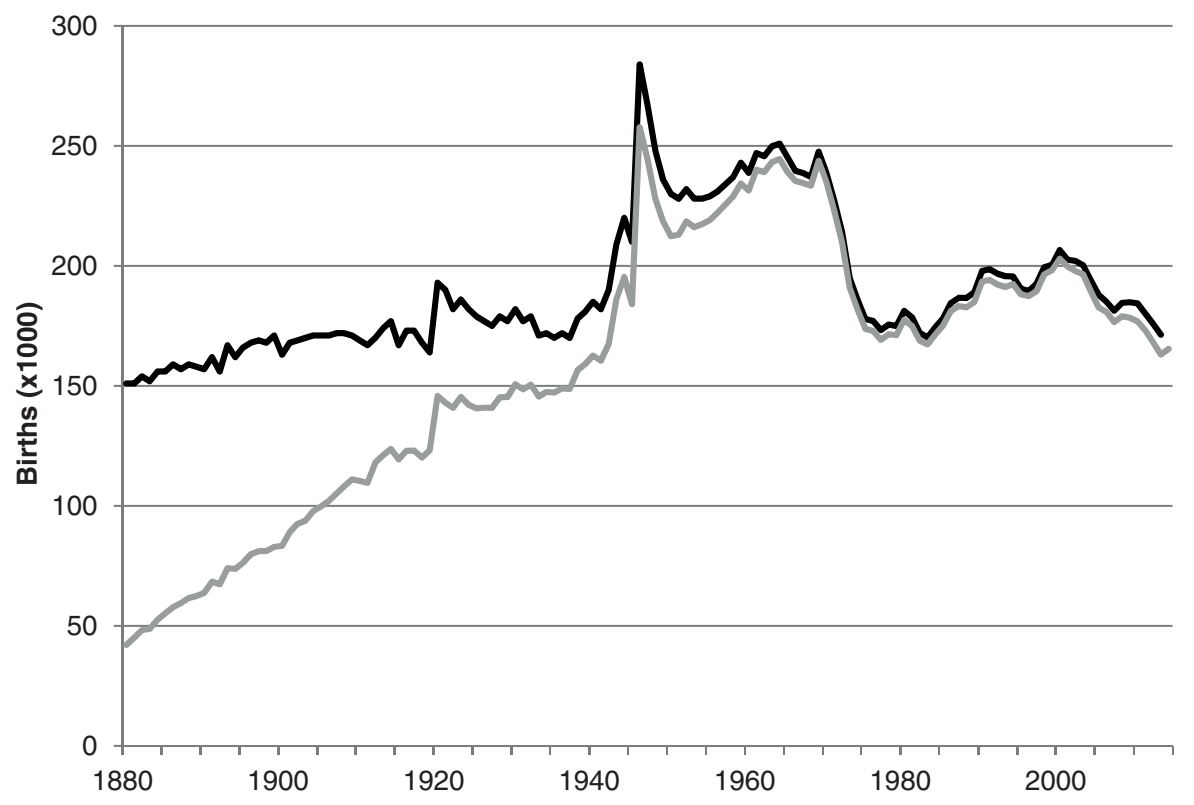

Figure 29.1: Number of births in the Netherlands according to Netherlands Statistics (black line) and number of births of individuals derived from the digitised Civil Registration (grey line). Differences in recent years (about 3\%) result from the requirement of Dutch nationality in our data selection.

the 12 provinces of the Netherlands. At a more detailed level, we have the 40, so-called COROP regions, ${ }^{2}$ which are defined on the basis of a central core and a certain homogeneity of their population. Another option is the presentation at the level of 24 dialect areas, as defined by Daan and Blok (1969), projected on the municipalities of 2007. For example, it is possible to see where the grandparents of current inhabitants (the latter of whom are 30-50 years old) of the province of Drenthe were born. The result will be presented at the municipal level, including within the province of Drenthe itself.

The choice to use the level of 443 municipalities in 2007 as a reference meant that we had to map places of birth to the corresponding 2007 municipalities. ${ }^{3}$ Fortunately almost all changes in municipal boundaries have been reductions of the number of municipalities through mergers and annexations, and therefore did not pose a problem. In a few cases, however, municipalities were split up or only partially annexed by a neighbouring municipality; as specific birth addresses were not known this could not be repaired. ${ }^{4}$

Another complication are hospital births. These accounted for 30\% of all deliveries in 1968 (De Haas-Posthuma and De Haas, 1968), increasing to 77\% in 2002 (Anthony et al., 2005). When the hospital is not in the municipality of the parental home, this confounds the results. No statistics of this effect are available, although it is likely to be small for the older generations, for which delivery at home was the standard. For the youngest generations (especially the

\footnotetext{
2 COROP refers to Coördinatie Commissie Regionaal OnderzoeksProgramma. The COROP areas correspond to the level 3 of the European Nomenclature of Territorial Units for Statistics (NUTS3).

${ }^{3}$ See www.bprbzk.nl/BRP/Informatiebank/publicaties.rvig.nl/Landelijke_tabellen/Landelijke_tabellen_32_t_m_60_ excl_tabel_35/Landelijke_Tabellen_32_t_m_60_in_csv_formaat.

${ }^{4}$ Only in the case of Ermelo (split into Ermelo and Nunspeet in 1972) did we keep the original undivided municipality.
} 
great-grandchildren) it is advisable to consider the place of residence during childhood, as this may give a better indication of the parental home at the time of birth. An example is the traditional village of Bunschoten, of which $44.3 \%$ of the great-grandchildren were born in the village itself and $23.6 \%$ in the nearby city of Amersfoort, while $62.6 \%$ live in Bunschoten and only $5.3 \%$ in Amersfoort. Not surprisingly Bunschoten has no hospital within its boundaries, while the nearest large hospital is in Amersfoort. In this case the figures for residence are likely more representative of the parental home during birth.

For places of birth outside the Netherlands (relevant for origins) we give percentages for major immigration countries in a separate list presented on the map. These are Belgium, Germany, Turkey, Morocco, Surinam, Netherlands Antilles, Dutch East Indies or Indonesia, Other (Europe), and Other (World).

\subsection{Migration Maps Per Generation}

Migration is visualised in maps by generation. Starting with a target group, the maps show the spread across the country for each generation of ancestors or descendants in a percentage per municipality, represented by a colour gradient on a (partly) logarithmic scale with ranges of 0 , $0.001,0.01,0.5,1,2,4,8,16,>32 \%$. By using mouse-over the actual percentage per municipality is shown.

By choosing to represent time through generation the family relation becomes clear, but the disadvantage is that the time periods may become increasingly longer for earlier (or later) generations or even overlap. This could imply that the same motives for migration may apply for different generations when they share, for instance, the same socio-economic conditions in some period of time. For the map showing origins (places of birth), the initial generation is born between 1957 and 1977 (a period of 20 years), the parents were born roughly between 1922 and 1952 (30 years), the grandparents between 1887 and 1927 (40 years), and the great-grandparents between 1852 and 1902 (50 years). Conversely, dispersion maps show the places of birth or residence of descendants, for an initial generation born between 1880 and 1900 (which is not shown in maps as most of them were deceased in 2006), children between 1905 and 1935, grandchildren between 1930 and 1970, and great-grandchildren between 1955 and 2007.

Percentages are calculated relative to the current number of inhabitants of a municipality (or any other available geographic entity) or the number of known ancestors per generation. It is assumed that the geographical distribution of the known individuals is representative of that of the larger population. While the coverage of generations is high enough in the Netherlands to consider this assumption to be valid, deviations will occur when parents are born in foreign countries. In that case the coverage of older generations is poor and their share will be underestimated. For example, in 2006 in Amsterdam 8.8\% of the inhabitants between 30 and 50 years of age were born in Surinam. For their parents this is a still somewhat realistic 7.8\%, but for their grandparents - who most likely lived in Surinam as well - the percentage drops to $2.6 \%$, because information about most of them is not available in the Dutch Civil Registration; for great-grandparents this is an even lower $0.47 \%$.

The migration maps are based on average figures per place of birth or residence in 2006. No individual migration history can be deducted from them. But at an aggregate level, a comparison of maps can illustrate moving patterns over time. For place of birth it should be kept in mind that this is an indication of the place of residence of the parents. A comparison of two subsequent origin maps (from older to younger generation) therefore shows - at an aggregate level - the migration between the parents' own birth place and their place of residence at the time children were born. This type of migration (leaving the parental home and starting a family) is among the most dominant in the life-course of individuals (see for example Kley, 2011). In addition, a comparison 
between the dispersion maps on the basis of place of birth and place of residence gives an indication of the move pattern during the (later) lifetime of people. For the older generations, especially, the place of residence in 2006 will be the final in life.

As a summary of how far people move between generations, the average distance between the places of birth or residence and the target area is calculated per generation. Because the distribution of these movements is positively skewed to higher distances, the median distance is used. This figure is only calculated for those individuals who do not live in the target area anymore. In addition the percentage of the population that did stay is shown for each generation.

It would be too complicated to include every possible gender combination for different generations. Nevertheless we provide results for the full female and male family lines, that is: mothers, grandmothers and great-grandmothers for women; and fathers, grandfathers and greatgrandfathers for men. By comparing male and female lines the effect of gender on migration can be studied.

\subsection{Implementation and Examples}

In this section we present some typical examples of the results which show the rich possibilities for exploration of migration, and the options for presentation and output. The examples stem from the border municipality of Emmen; the very traditional, religious village of BunschotenSpakenburg; and the town of Almere in the newly reclaimed polder of South-West Flevoland. At a larger geographic scale the migration patterns for the province of Friesland and for the area of the Limburgish dialect are shown. Finally, the level of migration across the Netherlands can be made visible by the percentage of great-grandparents and great-grandchildren that were born in the same municipality: the lower this percentage, the more migration has taken place.

Figure 29.2 shows a screenshot with the origin maps of the grandparents of those inhabitants of the municipality of Emmen that are between 30 and 50 years old. In the main map the origin percentages for foreign countries are shown as well, while the percentage per municipality is given as a mouse-over effect. The maps for the other generations are shown in a smaller size on the side which, when clicked, switch places with the main map. The simultaneous presentation of maps for four generations facilitates the understanding of migration patterns over roughly a century. By clicking a municipality the corresponding map will be shown, which allows for a fast comparison of migration patterns between different municipalities. On the right-hand side is the menu with options to choose one of the 443 municipalities, 40 COROP regions, 24 dialect areas or 12 provinces. The generation, gender line and type of map (origin or dispersion) can also be chosen. In the right lower corner, some overall statistics are presented.

We can see a typical dispersal pattern in Figure 29.2, with the largest group of grandparents born in Emmen itself (32.1\%) and a rapidly decreasing share the further a municipality lies from the town. The four nearest municipalities together account for $18.5 \%$, indicating that moving houses in the region itself is highly preferred. The big cities in the west of the country together account for $4.8 \%$ while the northern city of Groningen has a share of $1.3 \%$. Of interest in this border town are the grandparents born in Germany, constituting a relatively low cross-border migration of $2.7 \%$. Figure 29.3 demonstrates the origin and dispersion of the traditional and religious village of Bunschoten-Spakenburg, where over two-thirds of the fourth generation were born or still live. The visualisation allows us to quickly see that this is a municipality with little movement in or out over the last century, with the exception of the population concentration in the four major cities in the west of the country.

The opposite effect can be found in Figure 29.4, which presents the roots of inhabitants of the newly developed town of Almere (founded in 1976). This town was intended to house the quickly increasing population, especially from the nearby capital of Amsterdam, in which city $28 \%$ of 


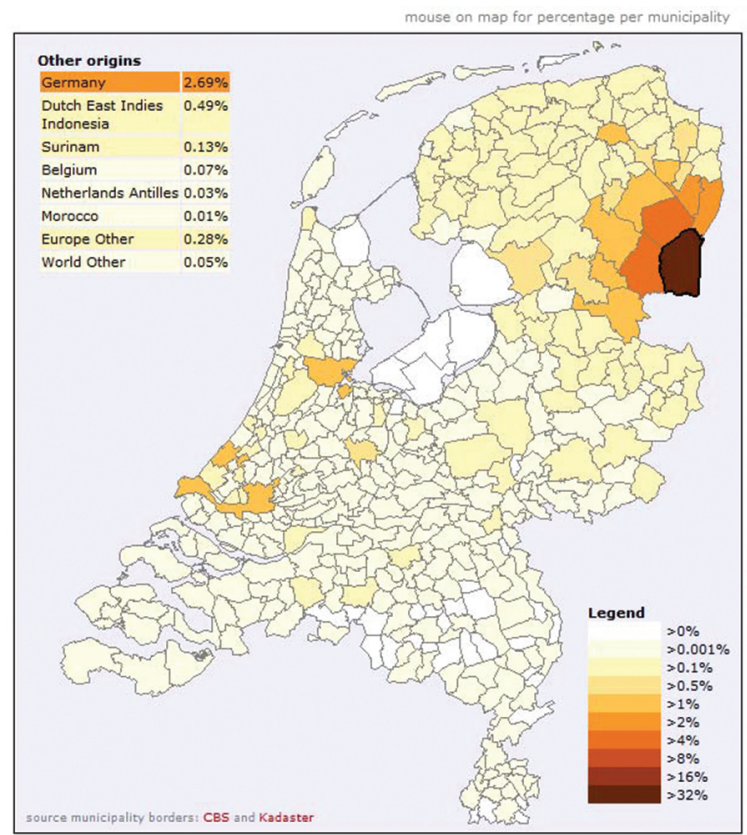

large map KML
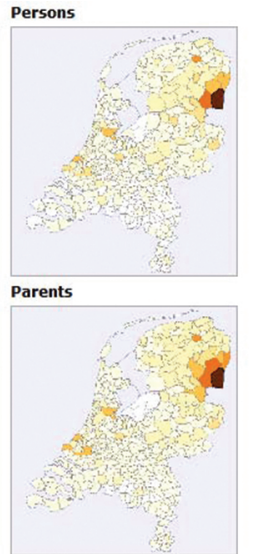

Greatgrandparents

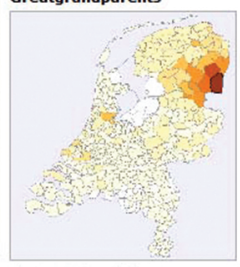

click map to switch

generations
Choose one municipality or area:

Municipality (or click in map):

Emmen

Region:

Choose.

Dialect area:

Choose

Province:

Choose

Generation:

30-50 years old

(- Parents

- Grandparents

Greatgrandparents

Gender line:

(-) All

- Female line

Male line

Type of map:

(- Origin map

Dispersion map (place of birth)

Dispersion map (place of residence)

Show map

Numbers

born in Emmen:

$59.0 \%$ of $30-50$ year olds

$46.0 \%$ of their parents

$32.1 \%$ of their grandparents

$22.9 \%$ of their greatgrandparents

if not born there,

distance to Emmen (median):

$54 \mathrm{~km}$ for $30-50$ year olds

$53 \mathrm{~km}$ for their parents

$47 \mathrm{~km}$ for their grandparents

$36 \mathrm{~km}$ for their greatgrandparents

Figure 29.2: Screenshot of the origin maps of the grandparents of the inhabitants of the municipality of Emmen who are 30-50 years of age. Note that the central polders were not yet reclaimed at the birth of this grandparent generation. (The colour legend is valid for all figures.)
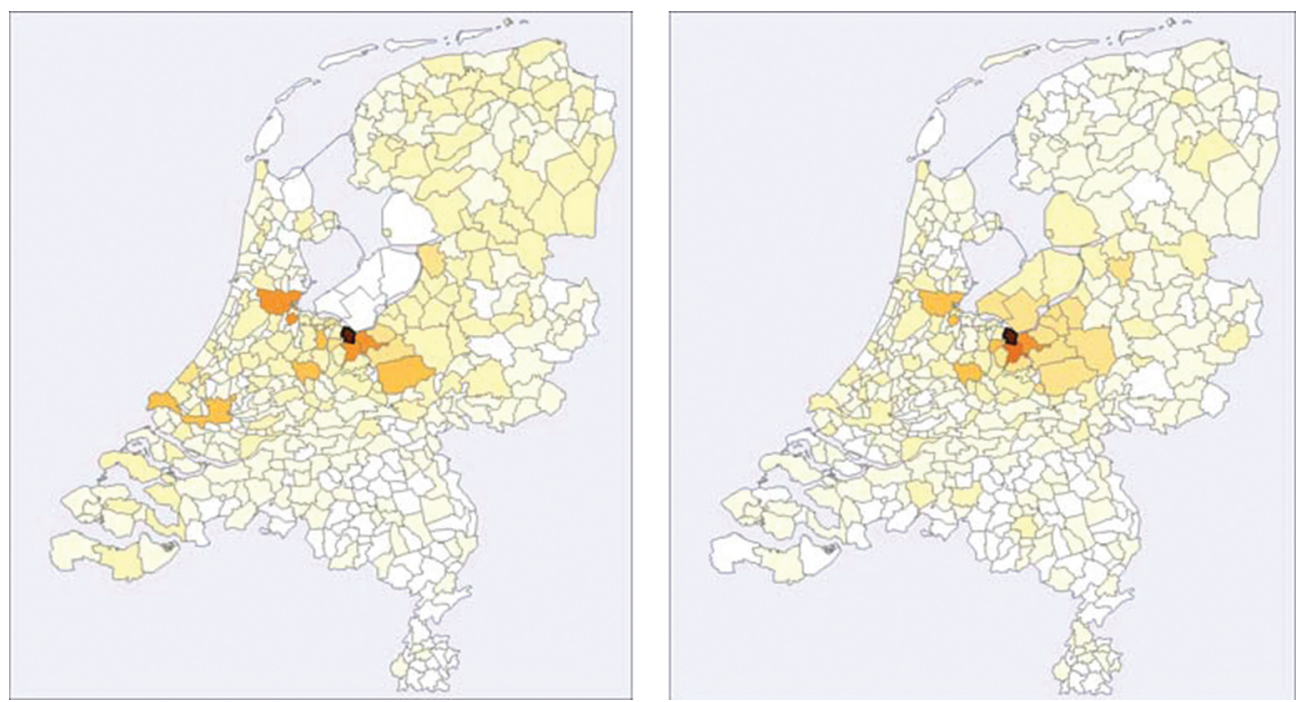

Figure 29.3: Origin and dispersion for the traditional village of Bunschoten-Spakenburg. Lefthand panel: birth place of great-grandparents (50\% in the village); right-hand panel: places of residence of great-grandchildren (63\% in the village). 


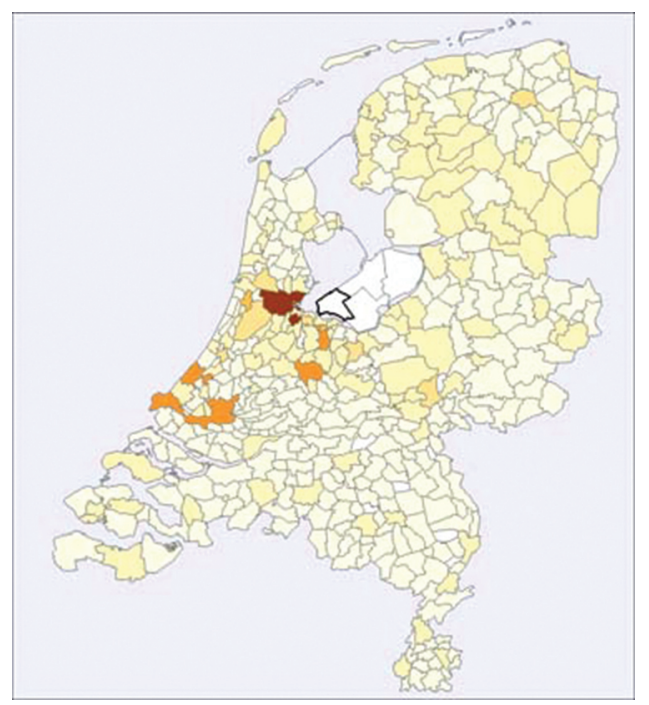

Figure 29.4: Birth places of parents of citizens of Almere, created in 1976 in the newly reclaimed polder of South-West Flevoland.
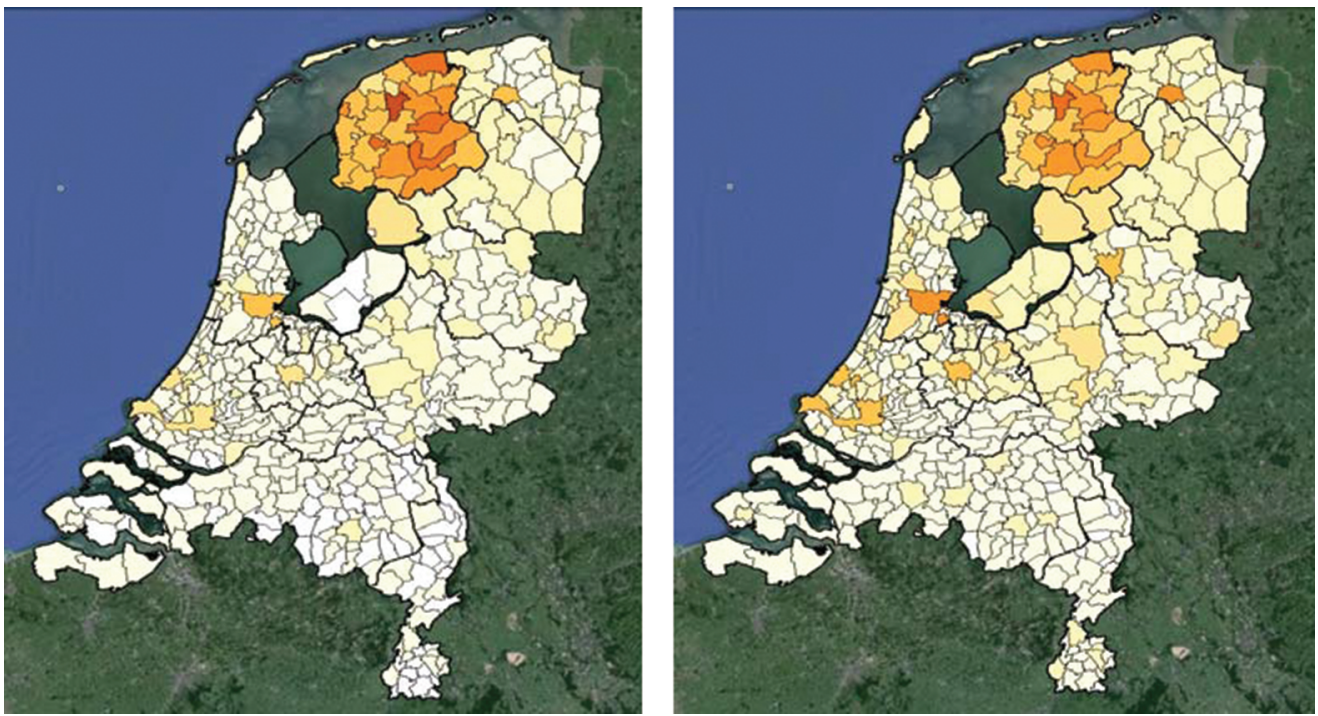

Figure 29.5: Origin and dispersion of inhabitants for the province of Friesland, projected on Google Earth. Left-hand panel: birth place of inhabitants who are 30-50 years of age (in 2006); right-hand panel: places of residence of great-grandchildren of inhabitants born 1880-1900.

the inhabitants of Almere were born. Another significant portion of the inhabitants were born in Surinam (10\%) and in other foreign countries (13.9\%).

Maps can be exported in KML format and projected on Google Earth. Figure 29.5 gives an example for origins and dispersion of inhabitants of the province of Friesland. This province has a strong identity, expressed by its own language. For all ancestral generations about $70 \%$ of the generation were born in Friesland itself, which is the highest percentage in the Netherlands. For descendants, $70 \%$ of the great-grandchildren were born in Friesland as well. 
Another approach, which is of linguistic interest, is a look into the origins of the population of a dialect area. This is shown in Figure 29.6 for the area of Limburgish, where 57\% of the greatgrandparents of the current population were born in the area. A strong border effect is noticeable as well, with the share of German ancestors at $6.5 \%$, several times higher than in other border regions.

A special option is the possibility to show the percentage of a generation that were born in the same municipality as their furthest ancestors or descendants. By choosing 'alle gemeenten' ('all municipalities') the site gives an overview of the extent to which people stay in the same municipality over multiple generations. This is shown for the fourth generation in Figure 29.7. Places

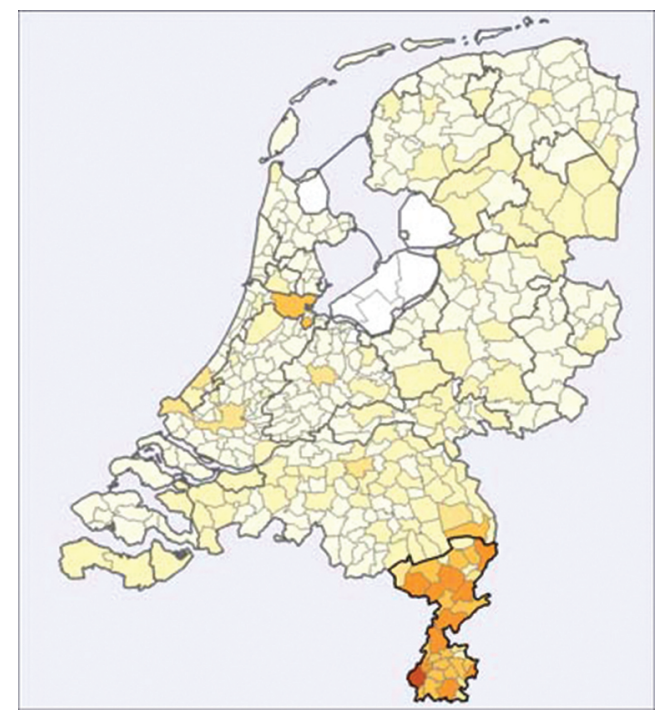

Figure 29.6: Origins in the dialect area of Limburgish, as birth places of great-grandparents.
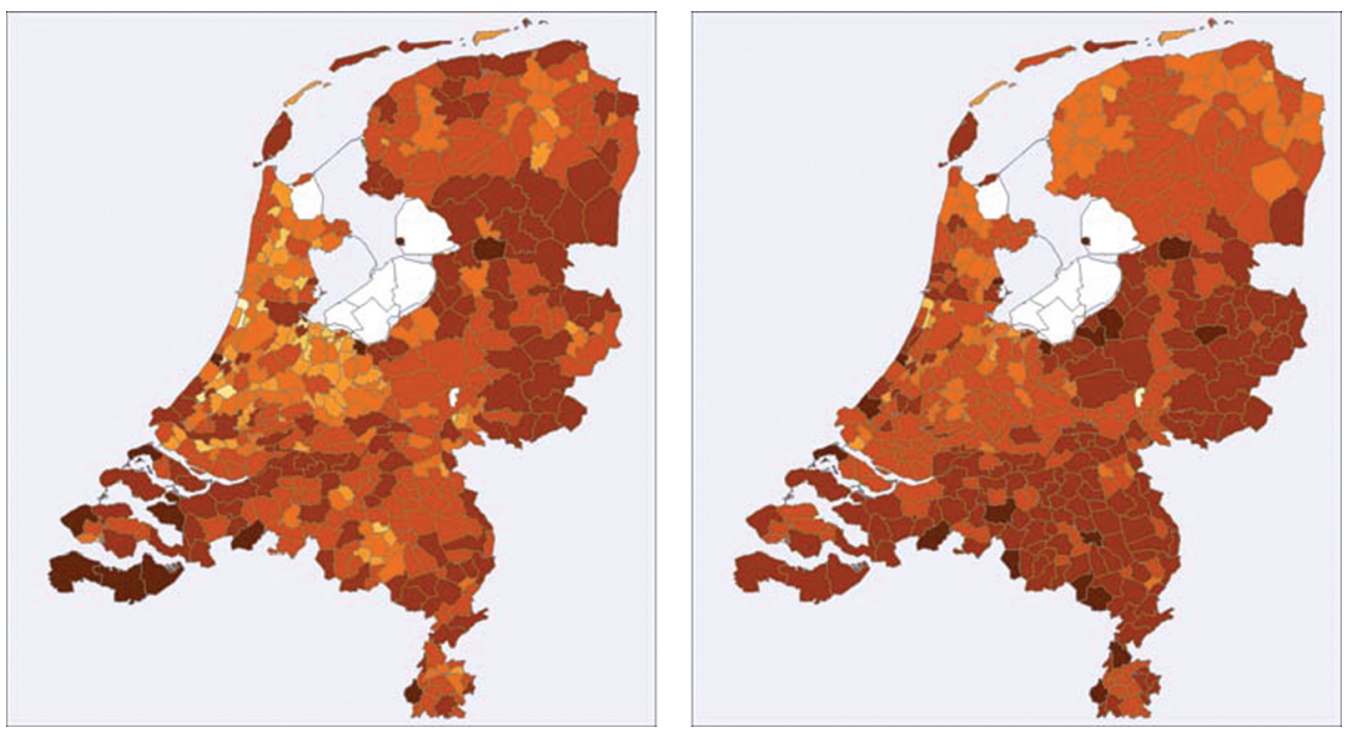

Figure 29.7: Percentage of great-grandparents that were born in the same municipality as their great-grandchildren (left-hand panel), and, conversely, percentage of great-grandchildren that still live in the same municipality as their great-grandparents (right-hand panel). 
that are dark in both panels have the least migration and the most stable population, notably Urk, Staphorst, Bunschoten-Spakenburg, Volendam, Katwijk and to a lesser extent Goedereede, Zundert and Maastricht - the first five of which are among the most orthodox Protestant municipalities. The areas in the west have had a significant influx from the rest of the country, resulting in a lighter shade.

\subsection{Conclusion}

The map tool allows for quick analysis of complex data with a geographical and time component. The current demonstrator on migration across generations can be helpful for the study of linguistic and social phenomena, by enhancing an understanding of the origins of the current population, which could serve as an inspiration for further research. An example of a demographic study of the distance between places of birth of great-grandparents and great-grandchildren is presented in Ekamper (2013).

\section{Appendix: Technical Background}

Maps are produced with the open source (GPLv2) mapping module Kaart, which can be found at www.meertens.knaw.nl/kaart/. A REST service, which powers the migration maps, is available and documented at www.meertens.knaw.nl/kaart/v3/rest/. Maps can be downloaded as KML files (via a button under each map) for presentation in Google Earth and for combination with other types of maps; downloading of maps as $1200{ }^{\star} 1320$ pixel PNG files for e.g. embedding in publications or presentations is also possible.

Information about municipalities, COROP areas, dialect areas and provinces, as well as all migration data underlying the maps, are available under the Creative Commons AttributionNonCommercial-ShareAlike 3.0 licence at www.meertens.knaw.nl/migmap/migrationdata/. This is also the source for migration data used by the Migmap application itself.

\section{Acknowledgements}

The MIGMAP (migration mapping) project, as part of the CLARIN-NL programme, was realised in 2012, with the website launched in January 2013. We wish to thank Peter Ekamper and Frans van Poppel from the Netherlands Interdisciplinary Demographic Institute (KNAW) for their helpful comments, and Folkert de Vriend for the integration of the results of the project in the CLARIN infrastructure.

\section{References}

Anthony, S, Amelink-Verburg, M P, Jacobusse, G W and Van der Pal-de Bruin, K M 2005 De Thuisbevalling in Nederland 1995-2002, rapportage over de jaren 2001-2002. Leiden: TNO Kwaliteit van Leven Jeugd.

Daan, J and Blok, D 1969 Van Randstad tot Landrand; toelichting bij de kaart: Dialecten en Naamkunde. Volume XXXVII, Bijdragen en mededelingen der Dialectencommissie van de Koninklijke Nederlandse Akademie van Wetenschappen te Amsterdam. Amsterdam: NoordHollandsche Uitgevers Maatschappij.

De Haas-Posthuma, J H and De Haas, J H 1968 Infant loss in the Netherlands. In: Vital and health statistics. Analytical studies 3. Washington D.C.: National Center for Health statistics. pp. 3-11. 
Ekamper, P and Bloothooft, G 2013 Weg van je wortels. De afstand tussen overgrootouders en achterkleinkinderen. DEMOS 29(2): 8.

Kley, S 2011 Explaining the Stages of Migration within a Life-Course Framework. European Sociological Review, 27(4): 469-86.

Prins, C J M and Kuijper, H 2007 Bevolkingsstatistieken onder het persoonskaartenstelsel en het GBA-stelsel: overeenkomsten en verschillen. Bevolkingstrends, 55: 14-33. 